Saudi Journal of Oral and Dental Research

Abbreviated Key Title: Saudi J Oral Dent Res

ISSN 2518-1300 (Print) |ISSN 2518-1297 (Online)

Scholars Middle East Publishers, Dubai, United Arab Emirates

Journal homepage: https://saudijournals.com/sjodr

Original Research Article

\title{
Knowledge and Awareness on Medico-Legal Aspects in Dentistry amongst Dental Graduates- An Original Research
}

Dr. Hasitha Gongura*, Dr. Bandaru Sai Krishna, Dr. Abhaya Vadlamudi, Dr. Monika Marripudi, Dr. Sri Pujith Dev, Dr. Anne Vivek

BDS, Drs. Sudha \& Nageswara Rao Siddhartha Institute of Dental Sciences, Chinoutpalli, Gannavaram Mandal, Andhra Pradesh, India

DOI: $10.36348 /$ sjodr.2020.v05i06.006

| Received: 03.06.2020 | Accepted: 21.06.2020 | Published: 26.06 .2020

*Corresponding author: Dr. Hasitha Gongura

Abstract

Aim: Purpose of our study was to assess the awareness of dentists regarding medico-legal aspects in dentistry. Methodology: Our study enrolled 100 BDS dentists as participants in the online survey. Questions premeditated to test the awareness of dental practitioners toward IC, types of consent, time for taking consent, consent form for minors, negligence for non-referral, indemnity policy etc. Results: The results show that around $78 \%$ of dentists knew about informed consent and its importance in medico-legal aspects. Around 67\% of dentists were aware of CPA and $45.7 \%$ of them had the knowledge about indemnity insurance policy and how it helps the dentist in case of medico-legal issues. Conclusion: In our study, we came across the fact that dentists participated in the survey had knowledge about informed consent but had less awareness about dental code of ethics. There was a need to increase awareness for medico-legal aspects in dental professionals.

Keywords: Forensic, medico-legal, dentistry, malpractice, CPA.

Copyright @ 2020: This is an open-access article distributed under the terms of the Creative Commons Attribution license which permits unrestricted use, distribution, and reproduction in any medium for non-commercial use (NonCommercial, or CC-BY-NC) provided the original author and source are credited.

\section{INTRODUCTION}

Dentistry and medicine today are professions dealing with health and well-being of an individual and in recent times, there has been an increased level of anxiety both within the medical professional and the patients at large. This can be attributed to the increase in medicolegal lawsuits against doctors in the past decade. Knowledge of dentistry and medicine is as important as knowing law governing their practice. Law and medicine go hand in hand, and an in-depth understanding of law is essential for a safe and sound clinical practice. Legal and ethical considerations are considered to be implicit and integrated parts of good clinical practice across the whole world. The disciplines of law and ethics in medical practice overlap in many areas and yet each has its unique parameters and distinct focus. The present times witness growth in public awareness of dental negligence in India. Monetary gains have led to the deterioration in the standard of patient care, and moreover, patients are becoming more aware of their rights [1]. Dental ethics is a moral obligation that encompasses professional conduct and judgment imposed by the members of the dental profession. The dentists (Code of Ethics) regulations were laid down by the Dental Council of India (DCI) in 1976 and later it was revised in the year
2014. It is the duty of every registered dentist to read these regulations, understand his responsibilities, and abide by the same. Dental jurisprudence is a set of legal regulations set forth by each state's legislature describing the legal limitations and regulations related to the practice of dentistry, dental hygiene, and dental assisting. There are several acts which have a direct and indirect bearing on the dental profession. The Dentists Act of 1948 is directly concerned with the statutory regulation of the dental profession. There are other enactments which in certain specific situations have an effect on the practicing dentist. These include the Consumer Protection Act (COPRA), Indian Contracts Act, and Indian Penal Code. A dentist should have acquaintance with the main provisions of these acts. He should know the responsibilities and precautions to be taken to avoid untoward happenings, including legal problems. He should also be familiar with his legal liabilities and the meaning of some terms used [2]. Due to lack of knowledge by dental practitioners or professionals, there is an increased risk of malpractice lawsuits in complex procedures [3]. Negligence is the breach of a legal duty of care. A breach of this duty gives the patient right to initiate action against negligence. All medical professionals, doctors, nurses, and other health-care providers are responsible for the health and safety of their parents and are expected to 
provide the quality of care [4]. Dental practitioners must be aware of the legal fundamentals, as there are greater possibilities of the dentist encountering such cases, particularly in the context of patient empowerment and also to provide efficient skilled work $[5]$.

Consent has become an essential part of patient treatment and management [6]. At present, the level of information given to the patients about an informed consent (IC) can vary in practice among dentists. Patients are demanding better services and more information about their treatment plan in healthcare disputes between both of them range from inadequate and inappropriate treatments to serious problems of dental malpractice and negligence. Before treatment, dentist must explain the formulated treatment for the patient and also to explain about the complications and other risk factors arise due to the proposed treatment, should also mention about the possibility of alternative treatment and appropriate consent should be obtained [7]. In India, the Consumer protection act [CPA] was enacted in 1986, to protect the interest of consumers. It was only on the 13th November 1995, which the medical/dental profession was brought within the ambit of CPA by the supreme court of India. Therefore, this study was performed to evaluate the level of knowledge and understanding related to Consumer Protection Act and Medico legal aspects among dental professionals [8]. Therefore, the present study is a humble effort to evaluate the knowledge of medico-legal aspects among dental practitioners so that training modules can be designed for safer and more effective delivery of dental care.

\section{AIM OF THE STUDY}

Purpose of our study was to assess the awareness of dentists regarding medico-legal aspects in dentistry and its importance in the current day scenario.

\section{METHODOLOGY}

Our study enrolled 100 BDS dentists as participants in the online survey. Of the total participants, 30 were female dental practitioners and rest were male dentists. They were sent a questionnaire based on their knowledge about Medico-legal aspects. The questions were in English language and in an openended format and were sent by email to them (Table-1). Questions premeditated to test the awareness of dental practitioners toward IC, types of consent, time for taking consent, consent form for minors, negligence for non-referral, indemnity policy, common cause for medicolegal litigation, exposure of medicolegal curriculum, consumer act protection, and need for the improvement of medicolegal issues knowledge among dentists. The responses from the participants were recorded on a Microsoft Excel sheet and were subjected to descriptive statistics.

\section{RESULTS}

The results show that around $78 \%$ of dentists knew about informed consent and its importance in medico-legal aspects. Around $45 \%$ take oral consent only whereas $7 \%$ of them take written as well as oral consent, rest usually take written consent. $69 \%$ of dentists took IC before operating the patient whereas only $34 \%$ of dentists provided a standardized IC form to the patients. In case of minors, $89 \%$ of dentists took permission from parents or guardians accompanying the minors. Dentists mostly faced problems in explaining the procedure to uneducated or less educated patients as they were not aware of dental health much. When asked about IPC for negligent homicide, only $12 \%$ of dentists mentioned about IPC section $304 \mathrm{~A}$, which shows lack of knowledge in dental ethics. Around $67 \%$ of dentists were aware of CPA and $45 \%$ of them had the knowledge about indemnity insurance policy and how it helps the dentist in case of medico-legal issues. Around $74 \%$ of the dental professionals knew about maintaining dental records for atleast 5 years for each patient (Table-2).

Table-1: Questionnaire utilized in the present study

\begin{tabular}{|l|l|}
\hline S. No & QUESTIONS \\
\hline 1 & Do you have an idea of informed consent? \\
\hline 2 & What are the Types of informed consent that you know of? \\
\hline 3 & What is the ideal time to get the informed consent from the patient? \\
\hline 4 & Do you know the procedure to take informed consent from minors? \\
\hline 5 & Do you provide informed consent form to the patient? \\
\hline 6 & Do you have an idea about the Indian Penal Code for negligent homicide? \\
\hline 7 & Do you get difficulties in taking informed consent? \\
\hline 8 & How to increase awareness about medico-legal aspects in dentists? \\
\hline 9 & Do you have any idea about indemnity policy? \\
\hline 10 & Are you aware of CPA? \\
\hline 11 & Are you aware of the time limit of maintaining a dental record for a patient? \\
\hline
\end{tabular}


Table-2: Results of Questionnaire Study

\begin{tabular}{|l|l|l|}
\hline S. No & QUESTIONS & PERCENTAGE \\
\hline 1. & Idea of informed consent & $78 \%$ \\
\hline 2. & Take oral consent only & $45 \%$ \\
\hline 3. & Take written consent only & $48 \%$ \\
\hline 4. & Take oral \& written consent both & $7 \%$ \\
\hline 5. & Take informed consent from parents in case of minor & $89 \%$ \\
\hline 6. & Take informed consent from just before operating & $69 \%$ \\
\hline 7. & Provide standardized informed consent form to the patient? & $34 \%$ \\
\hline 8. & Idea about the Indian Penal Code & $12 \%$ \\
\hline 9. & Idea about indemnity policy & $45 \%$ \\
\hline 10. & Awareness of CPA & $67 \%$ \\
\hline 11. & Maintaining dental records from past 5 years & $74 \%$ \\
\hline
\end{tabular}

\section{DISCUSSION}

Civic consciousness of medical and dental carelessness and slackness in India is growing which is causing upsurge in complaints regarding facilities, standards of professional skill and suitability of therapeutic and diagnostic methods. Negligence can occur in any aspect of proficient practice, whether history taking, advice, examination, testing or failing to test, reporting and acting on results of tests, or treatment. The standard is one of realistic care, not of excellence. The court will decide having gazed at to all the circumstances whether the health expert has been negligent [9]. Negligence is different from mistake or error of judgment [10]. Nowadays medical and dental practitioners should have knowledge of the law leading the practice of medicine because they both share same platform and go hand in hand. The drift in recent years toward codifying individual rights and liberty has clean down to the relationship between doctors and patients [11]. In today's scenario when we go through the dental and medical curriculum in India, there is more weight in developing the technical aspects and skills, but it lacks in ethical facet. The fresh mounting inclination of legal action against doctors is an issue of supreme concern which damages the esteem of white-collar job by media (electronic and print), certified accountability and decision making [12]. Various studies have been reported regarding the awareness and importance of consent from patients in dental practice. Additionally, the growing patient population is becoming more conversant and alert of their rights, as a result taking action by contacting the consumer forum to lodge their complaints [13]. Kumari et al., and Gupta et al., have reported a lack of knowledge in dentists about informed consent and its importance in medico legal issues. They have also emphasised that training on legal jurisprudence and legal medicine is necessary for dentists to guard themselves from civil or criminal proceedings [5, 15]. Sikka et al., stated that large number of dentists knew about Consumer protection act, but the basic awareness about rules and regulations was found to be low. They also observed that taking consent with written contract was not followed routinely, showing a lack of concern among the professionals [14]. Senthilkumar et al., and Haripriya through their studies inferred that there is an urgent need to update medical and dental health care professionals regarding medicolegal issues and consumer protection act to be on safer side legally. ${ }^{15}$ Prasad $\mathrm{S}$ et al. reported in their study that MDS faculty dental professionals have more awareness of consumer protection act compared to other dental professionals [16]. A dental practitioner in case of legal issues can take the help of a competent legal representative who specializes in such litigation. It is very important to maintain dental records so that it can be produced as evidence in the consumer court in the event of a malpractice and dental insurance claim. In our study, we found out that up to date knowledge is missing in our dental professionals in terms of medicolegal jurisdiction and it needs to be revamped as soon as possible and added to the curriculum of BDS undergraduate students, to make them aware of the present scenario.

\section{CONCLUSION}

In our study, we came across the fact that dentists participated in the survey had knowledge about informed consent but had less awareness about dental code of ethics. There was a need to increase awareness for medico-legal aspects in dental professionals.

\section{REFERENCES}

1. Zareen, I. N., \& Bhoj, M. (2019). Awareness of medicolegal aspects among dental practitioners. Drug Invention Today, 11(2):174-179.

2. Kesavan, R., Mary, A. V., Priyanka, M., \& Reashmi, B. (2016). Knowledge of dental ethics and jurisprudence among dental practitioners in Chennai, India: A cross-sectional questionnaire study. Journal of Orofacial Sciences, 8(2), 128134.

3. Al-Ammar, W., \& Guile, E. E. (2000). A one-year survey of dental malpractice claims in Riyadh. Saudi Dent J, 12(2), 95-99.

4. Murthy, K. K. (2007). Medical negligence and the law. Indian J Med Ethics, 4(3), 116-8.

5. Le Blang, T. R., Rosoff, A. J., \& White, C. editors. (2004). Informed consent to medical and surgical 
treatment. In: Legal Medicine. 6th ed. Philadelphia, PA: Mosby; 343.

6. Patil, A. M., \& Anchinmane, V. T. (2011). Medicolegal aspects of consent in clinical practice. Bombay Hospital Journal,53(2):203208.

7. Yadwad, B. S., \& Gouda, H. (2005). Consent-Its medico legal aspects. JAPI, 53, 891-894.

8. Goel, P., Sharma, P., Sharma, P., \& Vaish, S. (2018). Awareness about medico legal aspects and Consumer Protection Act (CPA) among dental fraternity. J Dent Specialities, 6(2), 131-135.

9. Gupta, M., Shrivastava, K., Mishra, S. K., Ahuja, R., Mishra, P., \& Kumari, S. (2018). Importance and awareness of medico legal issues in dental practice... Alarm call. Annals of Tropical Medicine and Public Health, 11(4), 103-107.

10. Goel, K., Goel, P., \& Goel, S. (2014). Negligence and its legal implications for dental professionals: A review. TMU J Dent, 1(3), 113-118.

11. Senthilkumar, S., Reddy, V. C., \& Ingle, N. A. (2013). Awareness of medico-legal issues among medical and dental college health professionals. Journal of Indian Association of Public Health Dentistry, 11(3), 44-50.

12. Baheti, M. J. (2015). Medico legal awareness: Where are we?-A survey among health professionals in Maharashtra and Haryana. International Journal of Public Health Research, 5(1), 525-530.

13. Al-Ammar, W., \& Guile, E. E. (2000). A one-year survey of dental malpractice claims in Riyadh. Saudi Dent J, 12(2), 95-99.

14. Aradhya, S., \& Acharya, S. (2012). Consumer Protection Act-Awareness?. International Journal Medical and Dental Science, 1(1), 1-8.

15. Haripriya, A., \& Haripriya, V. (2014). Knowledge about medical law and its negligence among doctors: A cross-sectional study. Int J Sci Res Publ, 4(5), 1-3.

16. Prasad, S., Menon, I., Dhingra, C., \& Anand, R. (2013). Awareness of Consumer Protection Act among dental health professionals in dental schools of Ghaziabad, India. Oral Health and Dental Management, 12(4), 262-268. 